\title{
Ultrasound and magnetic resonance imaging in the prenatal diagnosis of open spina bifida
}

\author{
Romeo Micu', Anca Lucia Chicea², Dan Georgian Bratu², Paula Nita², Georgiana Nemeti', \\ Radu Chicea ${ }^{2}$
}

${ }^{1}$ Obstetrics and Gynecology, Mother and Child Department, "Iuliu Hatieganu" University of Medicine and Pharmacy Cluj-Napoca, ${ }^{2}$ Department of Obstetrics and Gynecology, “Lucian Blaga” University Sibiu, Romania

\begin{abstract}
Open spina bifida, also known as spina bifida aperta is a neural tube defect involving the lack of closure of vertebral arches and associated meninges and/or spinal cord abnormalities. Ultrasound examination is the gold standard for the diagnosis of spina bifida aperta. It represents the main imaging tool used to ascertain this diagnosis early in gestation. Three-dimensional ultrasound is necessary to detect the level and the size of the defect. Magnetic resonance imaging (MRI) represents a more sensitive tool, giving specific information of the defect and associated anomalies, playing an important role in ruling out differential diagnosis. Due to the advent of MRI use, it is possible today to achieve in utero treatment of fetuses with this pathology. The aim of the current review is to provide an update of literature regarding the role of ultrasound and MRI in the prenatal diagnosis of spina bifida aperta.
\end{abstract}

Keywords: spina bifida; magnetic resonance imaging; Chiari II; ultrasound; prenatal diagnosis.

\section{Introduction}

Spina bifida is a congenital malformation belonging to the larger category of neural tube defects with a reported incidence of 1 to 1000 births [1,2]. It is the most common central nervous system (CNS) malformation compatible with life, represented by the lack of dorsal closure of the vertebrae which lack neural arches and may be located at any level along the spine. These defects can be classified into closed when the spinal defect is skin covered (spina bifida occulta) or open (spina bifida aperta) when the lesion site is not covered by skin and involves abnormalities of the meninges and/ or the spinal cord (meningocele/myelomenigocele). Spina bifida aperta is frequently associated with Chiari type II

Received 28.09.2017 Accepted 05.11.2017

Med Ultrason

2018, Vol. 20, No 2, 221-227

Corresponding author: Georgiana Nemeti

Obstetrics and Gynecology,

Mother and Child Department,

Clinicilor 3-5, 400006, Cluj-Napoca, Romania

Phone: 0723565256 , Fax: 0040264450.115

E-mail: georgiana_nemeti@yahoo.com malformation, which is an abnormality of the posterior fossa characterized by the herniation of the cerebellum and brainstem through the foramen magnum [3]. Also, due to mechanical obstruction, it is often associated with ventriculomegaly $[4,5]$.

Prenatal ultrasonography (US) represents the gold standard in fetal neural defects evaluation and diagnosis, whereas fetal magnetic resonance imaging (MRI) is used to refine the diagnosis. The role of prenatal diagnosis is to provide information that may help medical staff in counseling future parents regarding the pathology of their offspring, the therapeutic methods available in utero/postpartum, and the expected short and long-term outcome $[6,7]$.

The aim of this review is to provide a literature update regarding the contribution of prenatal US and fetal MRI evaluation in the prenatal diagnosis of spina bifida aperta.

\section{D ultrasonography in spina bifida}

The main method used when screening for fetal anomalies is represented by two-dimensional (2D) US. The growing interest in performing anatomical assess- 


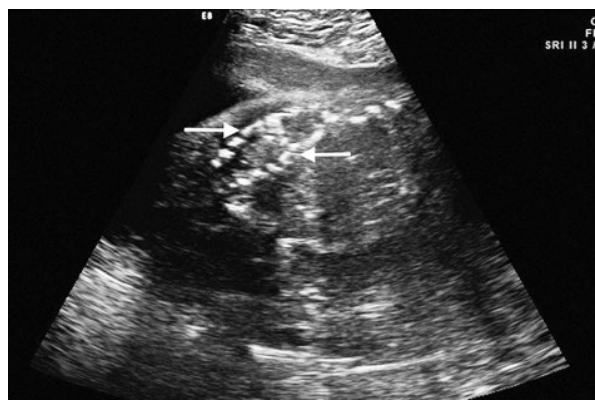

Fig 1. 2D ultrasound of myelomeningocele of the lumbar spine cord at 25 weeks of gestation (between arrows).

ment for Down syndrome in the first trimester of pregnancy has led to an improvement in 2D US resolution $[8,9]$. Several studies show a high sensitivity and specificity of 2D US in terms of evaluating bone anomalies, noting an increase in the detection of skeletal defects [8,10-14]. The technical specifications of the US machine, such as a high-resolution and high frame rate, are essential to obtain quality images $[6,15,16]$. It is recommendable to visualize structures in at least two planes to lower the risk of artifacts. The diagnosis of spina bifida aperta was usually made at the time of the second trimester scan, between 18-24 weeks of gestation $[1,5,6,14]$ by visualization the spinal cord herniation (fig 1)

Nowadays the trend is to detect the malformation in the first trimester or early in the second trimester of pregnancy. Fetal CNS evaluation requires examination in the transthalamic, transcerebellar, and transventricular planes [17]. These planes allow the visualization of skull contour, falx cerebri, cavum septum pellucidum, cerebellum, cisterna magna, thalamus, posterior and lateral horns of the ventricles [6,18-21]. At this gestational age, examination of the entire length of the spinal cord may be difficult, depending also on the fetal position, thus the diagnosis of spina bifida aperta is often based on intracranial indirect findings as the fetal head is easier to examine $[1,8,16,22]$. These indirect signs of myelomeningocele are the „lemon sign" - biconcave frontal bones and ,banana sign" - an abnormal, curved and thin form of the cerebellum (fig 2) $[1,6,8]$. Ventriculomegaly is also, a common finding in the Chiari II malformation but is nonspecific for this kind of pathology.

In fact, when the antero-posterior diameter of the cisterna magna and the shape of the cerebellum are normal, a type II Chiari malformation can be excluded [22].

Another useful 2D US parameter is the clivus-supraocciput angle which is represented by the angle obtained on the mid sagittal section by drawing two lines between the clivus and the supraocciput. The value of

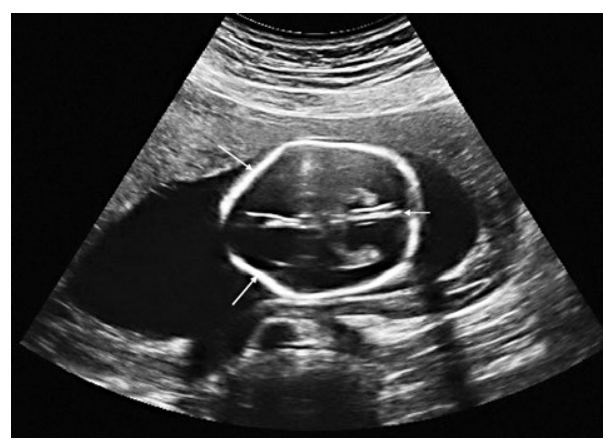

Fig 2. Lemon and banana sign (arrows) - 19 weeks of gestation

the angle is a specific parameter for detecting the Chiari II abnormality and may be used in the differentiation of other causes of ventriculomegaly [23]. D'Addario et al published a comparative study on 310 pregnant women with normal fetuses and 44 fetuses diagnosed with ventriculomegaly due to different pathologies [16]. Results showed that the value of the clivus-supraocciput angle was below the $5^{\text {th }}$ percentile on the nomogram in fetuses with Chiari II malformation, suggesting a smaller size of the posterior fossa.

\section{D ultrasonography in spina bifida}

Three-dimensional (3D) US has evolved very fast over the past few years due to high performance software in engineering, architecture and design [24]. The advantage of this technique is that it allows the acquisition of volumetric data which can be processed by the operator even after the completion of the examination $[10,24,25]$. It also allows multiple views of surfaces and structures as well as of certain tissues such as bones to be extracted from the volumetric data set and also the reconstruction of the fetal bones while focusing the examination on the area of interest $[8,24]$. Recent data from the literature advocates for 3D US in assessing skeletal anomalies and phenotypic features of the fetuses [8,24-26]. There is an ongoing debate about the contribution of 3D US over 2D US in the diagnosis and management of spina bifida aperta. Several publications support the 3D US advantages over 2D US, due to the possibility of showing a continuous structure image of the spinal cord rather than an independent one characteristic to 2D views (fig 3) $[6,27,28]$.

In order to facilitate the clinicians' diagnosis of the Chiari II malformation, Leibovitz et al aimed to elaborate nomograms for the dimensions of the posterior fossa (PF) applicable in the $2^{\text {nd }}$ and $3^{\text {rd }}$ trimester of pregnancy, by assessing the mid-sagittal cranial plane with threedimensional multiplanar imaging [22]. In addition, the 
study compared the PF measurements between normal fetuses and those with neural tube defects. The nomograms were created using scans performed on 378 normal fetuses with a gestational age between 15-35 weeks. The area of the posterior fossa (PFA) and the perimeter of the posterior fossa (PFP) were included as parameters in the growth graphs.

The authors delimited the PF according to the following landmarks: from clivum to tentorium (CTD) and from the level of the upper mesencephalic edge to the occipital bone (TOD). The results showed a liniar relationship between the gestational age and PFA, PFP, TOD and CTD in normal developed fetuses. The study identified 39 fetuses with PF anomalies (including 11 cases of Chiari II malformation) which were analyzed by calculating z-scores for PFA, PFP, TOD, and CTD and compared to the developed nomograms. In all 11 cases with Chiari II malformation, highly contrasting z-scores for the PF size parameters were demonstrated. Moreover, PFA, showed the greatest deviation in z-scores, which ranged between -2.66 and -7.08 (mean, -5.31) meaning the size of posterior fossa was significantly smaller than nomograms. Another relevant study conducted by Scheier et al [6] on 11-13 weeks foetuses with spina bifida found important differences in the size of the posterior fossa in Chiari II malformation cases, supporting, previous data reported, even in earlier gestational age.

The largest study including 1030 fetuses among which 30 were diagnosed with spina bifida aperta measured the changes occurring in the first trimester of pregnancy in the PF. In all fetuses the brain stem and brain stem to occipital bone diameter (BSOB) were measured in the mid-sagittal view. In the control group, the brain stem to BSOB ratio decreased and the brain stem and BSOB diameter increased significantly with crown-rump length. In $96.7 \%$ of the cases with spina bifida aperta, the brain stem diameter was above the 95th percentile compared to the control group. The brain stem to BSOB ratio was above the 95th percentile in all cases and the BSOB diameter was below the 5 th percentile in $86.7 \%$ of cases, all of these findings suggesting a smaller size of PF already from the first trimester of pregnancy [29].

These results are one of the first reported and of high importance as the current trend is to establish the diagnosis of spina bifida diagnosis at the end of the $1^{\text {st }}$ trimester or early in the $2^{\text {nd }}$ trimester of pregnancy [30-32]. For an accurate US evaluation, it is important that the examiner should be familiar with spine and intracranial structures anatomy, according to the gestational age.

Different attempts to use other parameters were described. Several published papers analyzed the possibility of diagnosing spina bifida at the end of the first

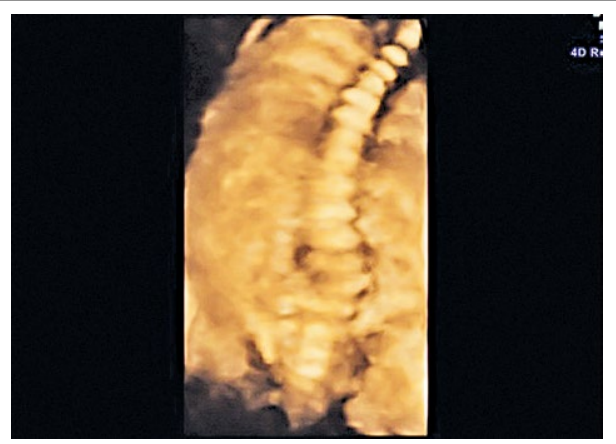

Fig 3. 3D ultrasound of myelomeningocele at 25 weeks of gestation

trimester of pregnancy by 2D and 3D US by evaluating other US markers such as: the anteroposterior diameter of the cisterna magna and the fourth ventricle (intracranial translucency), the brainstem diameter, the brainstem-occipital bone distance, the diameter of the roof of the third ventricle and the diameter of the aqueduct of Sylvius, in axial or mid-sagittal planes [33-36]. From all these measurements the antero-posterior decrease of the intracranial translucence (fourth ventricle) and the cisterna magna obliteration were proven to be the most common markers associated with spina bifida aperta in the first trimester of pregnancy [7,15,29,32-37].

Loureiro et al published a study seeking changes in the cerebral ventricular system in fetuses with spina bifida aperta with gestational ages between 11-13 weeks [28]. Four hundred and two fetuses were included in the study, among them 10 fetuses with spina bifida aperta. They were evaluated by transvaginal US with the acquisition of 3D volumes of the brain. Lateral ventricular measurements, third ventricle roof diameter, aqueduct of Sylvius diameter and fourth ventricle diameter were performed. Unlike normal fetuses, in fetuses with spina bifida aperta the diameter of third and fourth ventricle, aqueduct of Sylvius, and lateral ventricular area were significantly smaller. These results are concordant with findings that the amount of cerebrospinal fluid is reduced in fetuses with spina bifida aperta.

Knowing the exact level of the spinal defect is an important factor when choosing therapeutical methods. Therefore, its precise identification is mandatory. In this regard, Buyukkurt et al aimed to predict antepartum the level of the defect in fetuses with spina bifida by using 3D imaging. Afterwards, postpartum, the exact level of the spinal aperture was confirmed by radiography or by autopsy (in the case of antepartum fetal demise).The detection rate of the defect's level using this technique was $79 \%$, suggesting that the method is a useful tool for prenatal determination of lesion level in spina bifida [23]. 


\section{US vs MRI in spina bifida}

US examination is constantly evolving thus enabling the evaluation of fine structures, being the main imaging tool used to ascertain the diagnosis of spina bifida aperta early in gestation. US is less expensive, more widely accessible than MRI and is the main method of detecting fetal malformations in the first trimester of pregnancy. Moreover, it has an important role in deciding when to use more complex investigation methods, such as fetal MRI, and is certainly the basis for in utero surgical treatment of spina bifida aperta. Even though it is considered the gold standard for the diagnosis is has several disadvantages especially in case of obese women where the degree of penetration of the US beam is low or in case of oligoamnios when visualisation and diagnosis could be difficult. Low penetration (amplified by the increase of the gestational age) through fetal bone tissue, makes US unable to fully evaluate the fetal skeleton.

Another limit of the US examination is found in cases of cerebellum or cerebral trunk herniation, where it cannot establish the severity of this anomaly. In all these cases MRI proofs as a superior method confirming the diagnosis and also revealing associated fetal abnormalities. MRI represents an important imaging tool, neurosurgeons can rely on, in order to counsel future parents regarding the type of intervention that the fetus might need. It is also the main method for monitoring the postoperative outcome of the fetuses [38].

Early studies on fetal MRI began in the 1980's. Initially, MRI was only used for CNS evaluation. Due to active fetal movements the examination was impaired and that represented a major drawback. With the development of fast-moving sequences that take less than 20 seconds, this limit has been eliminated and fetal malformations can be detected much more easily and accurately
$[38,39]$. Due to the high resolution of the soft tissues, a MRI examination reveals a clear distinction between maternal and fetal organs, and has the advantage of acquiring more data in comparison to US [40-42]. MRI images may be obtained in sagittal, transverse, and coronary sections. Being a non radiant method it is safe to use during pregnancy. The use of contrast media is not recommended due to its transplacental passage [43-45].

MRI allows a more accurate prenatal diagnosis than US, due to the detailed description of the cerebellum and the posterior fossa and can give a full assessment of the spinal lesion or other complications in Chiari II malformation (fig 4a) [42,46-49].

Some specific features of in utero Chiari II malformation, such as cerebellum herniation and possible changes in brain parenchyma signal can be better evaluated by fetal MRI than US (fig 4b) [50].

Being the investigation that establishes the definitive diagnosis as well the site of the spinal lesion (fig 4c) [1], and because it is less dependent of the fetal position [51], MRI brings important information when it comes to the in utero or postpartum surgical treatment options of fetuses with spina bifida aperta [2].

Recent studies discuss this issue and emphasize the advantages and disadvantages of such procedures in Chiari type II malformation [52]. Beghly et al showed that the low antero posterior diameter of the PF associated with hydrocephalus is one of the characteristic MRI images of Chiari II malformation [53]. The confirmation of cerebellum herniation, which can only be performed by fetal MRI, is one of the main criteria for in utero surgery of myeolomeningocele [54].

In the last years, fetal surgery has evolved, providing therapeutic options for treating congenital malformations. In utero surgery for myelomeningocele is not indicated before 18 weeks of gestation due to insufficient

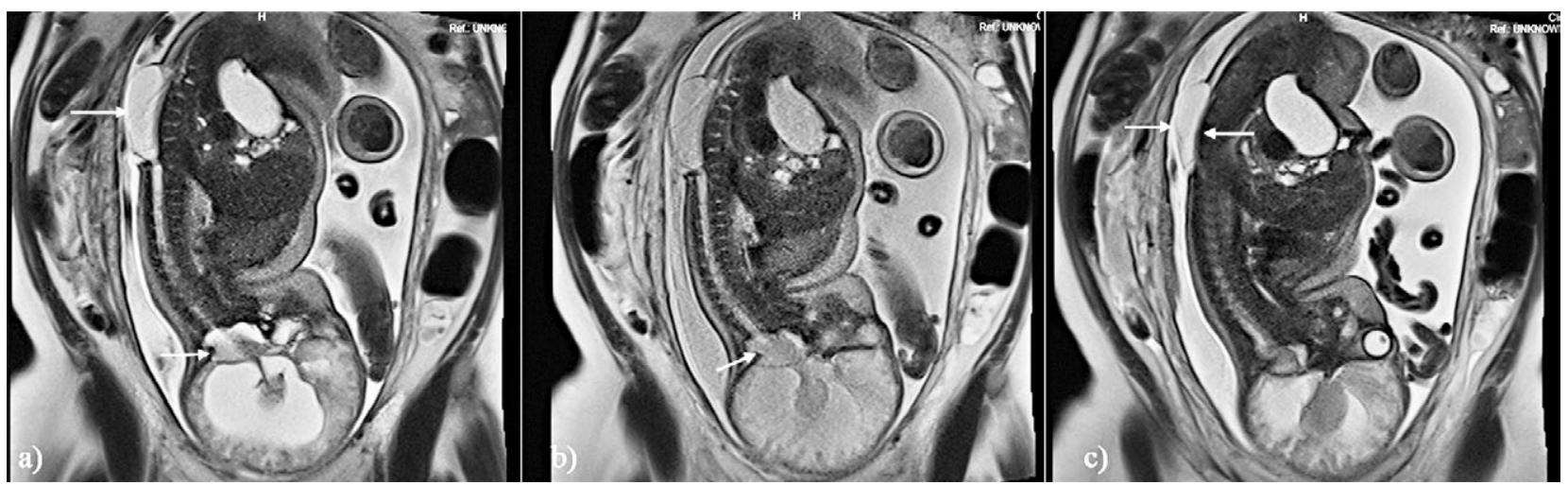

Fig 4. MRI examination in a case with Chiari II malformation at 28 weeks of gestation: a) MRI T2 - weighted sagittal view. The cerebellum herniation (superior arrow) and the spinal cord defect (inferior arrow; b) MRI T2 - weighted sagittal view,cerebellum herniation (arrow); c) MRI T2 weighted sagittal view - lumbar lesion (between arrows). 
fetal growth and increased tissue fragility [55]. After 32 weeks of gestation, the risk of preterm birth is far too high compared to the benefits of surgery so, intrauterine repair of myelomeningocele is usually performed between 19-25 weeks of gestation [56,57].

A study regarding the surgical treatment of myelomeningocele named Management of Myelomeningocele (MOMS), has clearly shown the advantages and risks of intrauterine surgery [58]. The purpose of the study was to evaluate whether results obtained from in utero surgery performed between 19-25 weeks of gestation are superior to those obtained from postpartum surgery. The MOMS study showed that at the age of one year only $42 \%$ of the prenatal surgery group needed ventriculoperitoneal (VP) shunting as compared to $82 \%$ of the postnatal surgery group. The study also revealed a significant improvement in child neuromotor function at two and a half years. They found that $42 \%$ of the children from the prenatal surgery group were walking without support while only $21 \%$ of the children from the postnatal surgery group were walking without help. Compared to the postnatal surgery group, hindbrain herniation was significantly reversed in the fetal surgery group. The MOMS study also highlighted some of the possible complications of in utero surgery such as increased risk of preterm birth, premature rupture of membranes and oligoamnios.

The repair of myelomeningocele in utero, with all the benefits it offers, is dependent on the MRI examination which establishes whether the criteria for the surgery are met.

\section{Conclusions}

Early detection of open spina bifida is mandatory for the option of intrauterine surgery which has better results in comparison to postpartum surgery in terms of offspring outcome. Prenatal US represents at this point the gold standard for the detection of spina bifida aperta in early gestation. Furthermore, 3D US is employed to offer supplementary information in the determination of the level and the size of the spinal injury. MRI, on the other hand, represents an additional high resolution imaging tool providing more specific information and playing an important role in the differential diagnosis of fetal central nervous system malformations. US and MRI are complementary examinations which assist clinicians in providing adequate parental counselling, choosing the appropriate therapeutic strategy and to predict fetal outcome.

\section{Conflict of interest: none}

\section{References}

1. Copp AJ, Adzick NS, Chitty LS, Fletcher JM, Holmbeck GN, Shaw GM. Spina bifida. Nature Rev Dis Primers 2015;1:15007.

2. Iliescu D, Comanescu A, Antsaklis P, et al. Neuroimaging parameters in early open spina bifida detection. Further benefit in first trimester screening? Rom J Morphol Embryol 2011;52:809-817.

3. Coleman BG, Langer JE, Horii SC. The diagnostic features of spina bifida: the role of ultrasound. Fetal Diagn Ther 2015;37:179-196.

4. Sepulveda W, Wong AE, Sepulveda F, Alcale JL, Devoto JC, Otayza F. Prenatal diagnosis of spina bifida: from intracranial translucency to intrauterine surgery. Childs Nerv Syst $2017 ; 33: 1083-1099$.

5. Meller C, Aiello H, Otaño L. Sonographic detection of open spina bifida in the first trimester: review of the literature. Childs Nerv Syst 2017;33:1101-1106.

6. Scheier M, Lachmann R, Pětroš M, Nicolaides KH. Threedimensional sonography of the posterior fossa in fetuses with open spina bifida at 11-13 weeks' gestation. Ultrasound Obstet Gynecol 2011;38:625-629.

7. Markov D, Pavlova E, Atanasova D, Markov P, Ivanov S. Absent intracranial translucency-new ultrasound marker for spina bifida at 11-13+6 weeks of gestation. Akush Ginekol (Sofia) 2010;49:56-60.

8. Noel AE, Brown RN. Advances in evaluating the fetal skeleton. Int J Womens Health 2014;6:489-500.

9. Szabó A, Szili K, Szabó JT, et al. Nasal bone length: prenasal thickness ratio: a strong 2D ultrasound marker for Down syndrome. Prenat Diagn 2014;34:1139-1145.

10. Wallny T, Schild RL, Fimmers R, Hansmann ME. Threedimensional sonographic evaluation of the fetal lumbar spinal canal. J Anat 2002;200:439-443.

11. Dicke JM, Piper SL, Goldfarb CA. The utility of ultrasound for the detection of fetal limb abnormalities - a 20year single-center experience. Prenat Diagn 2015;35:348353.

12. Zheng LP, Gong LL, Guo FC, Chang HB, Liu GH. Application research on three-dimensional ultrasonic skeletal imaging mode in detecting fetal upper jaw bone. Int J Clin Exp Med 2015;8:12219-12225.

13. Guguloth A, Aswani Y, Anandpara KM. Prenatal diagnosis of hypophosphatasia congenita using ultrasonography. Ultrasonography 2016;35:83-86.

14. Cameron M, Moran P. Prenatal screening and diagnosis of neural tube defects. Prenat Diagn 2009;29:402-411.

15. Bahlmann F, Reinhard I, Schramm T, et al. Cranial and cerebral signs in the diagnosis of spina bifida between 18 and 22 weeks of gestation: A German multicentre study. Prenat Diagn 2015;35:228-235.

16. D'Addario V, Pinto V, Del Bianco A, et al. The clivussupraocciput angle: a useful measurement to evaluate the shape and size of the fetal posterior fossa and to diagnose Chiari II malformation. Ultrasound Obstet Gynecol 2001;18:146-149. 
17. Bethune M, Alibrahim E, Davies B, Yong E. A pictorial guide for the second trimester ultrasound. Australasian $\mathrm{J}$ Ultrasound Med 2013;16:98-113.

18. De Keersmaecker B, Claus F, De Catte L. Imaging the fetal central nervous system. Facts Views Vis Obgyn 2011;3:135-149.

19. Callen P. Ultrasonography in Obstetrics and Gynecology. Philadelphia: Saunders Elsevier, 2008.

20. Merz E. Ultrasound in Obstetrics and Gynecology. Stuttgart: Georg Thieme Verlag, 2013.

21. International Society of Ultrasound in Obstetrics and Gynecology Education Committee. Sonografic examination of the fetal nervous system: guidelines for performing the 'basic examination' and the 'fetal neurosonogram'. Ultrasound Obstet Gynecol 2007;29:109-116.

22. Leibovitz Z, Haratz KK, Malinger G, Shapiro I, Pressman C. Fetal posterior fossa dimensions: normal and anomalous development assessed in mid-sagittal cranial plane by three-dimensional multiplanar sonography. Ultrasound Obstet Gynecol 2014;43:147-53.

23. Buyukkurt S, Binokay F, Seydaoglu G, et al. Prenatal determination of the upper lesion level of spina bifida with threedimensional ultrasound. Fetal Diagn Ther 2013;33:36-40.

24. Paoletti D, Robertson M, Sia SB. A sonographic approach to prenatal classification of congenital spine anomalies. Australasian J Ultrasound Med 2014;17:20-37.

25. Grigore M, Iliev G, Gafiteanu D, Cojocaru C. The fetal abdominal wall defects using 2D and 3D ultrasound. Pictorial essay. Med Ultrason 2012;14:341-347.

26. Grigore M, Iliev G. Diagnosis of sacrococcygeal teratoma using two and three-dimensional ultrasonography: two cases reported and a literature review. Med Ultrason 2014;16:274-277.

27. Werner Júnior H, dos Santos JL, Belmonte S, et al. Applicability of three-dimensional imaging techniques in fetal medicine. Radiol Bras 2016;49:281-287.

28. Loureiro T, Ushakov F, Montenegro N, Gielchinsky Y, Nicolaides KH. Cerebral ventricular system in fetuses with open spina bifida at 11-13 weeks' gestation. Ultrasound Obstet Gynecol 2012;39:620-624.

29. Lachmann R, Chaoui R, Moratalla J, Picciarelli G, Nicolaides KH. Posterior brain in fetuses with open spina bifida at 11 to 13 weeks. Prenat Diagn 2011;31:103-106.

30. Tortori-Donati P, Rossi A, Cama A. Spinal dysraphism: a review of neuroradiological features with embryological correlations and proposal for a new classification. Neuroradiology 2000;42:471-491.

31. Lachmann R, Sinkovskaya E, Abuhamad A. Posterior brain in fetuses with Dandy-Walker malformation with complete agenesis of the cerebellar vermis at 11-13 weeks: a pilot study. Prenat Diagn 2012;32:765-769.

32. Orlandi E, Rossi C, Perino A, Cucinella G, Orlandi F. Prospective sonographic detection of spina bifida at 11-14 weeks and systematic literature review. J Matern Fetal Neonatal Med 2016;29:2363-2367.

33. Kose S, Altunyurt S, Keskinoglu P. A prospective study on fetal posterior cranial fossa assessment for early detection of open spina bifida at 11-13 weeks. Congenit Anom (Kyoto) $2017 \mathrm{Apr} 5$. doi:10.1111/cga.12223.
34. Kappou D, Papastefanou I, Pilalis A, Kavalakis I, Kassanos D, Souka AP. Towards detecting open spina bifida in the first trimester: the examination of the posterior brain. Fetal Diagn Ther 2015;37:294-300.

35. Karl K, Heling KS, Chaoui R. Fluid area measurements in the posterior fossa at 11-13 weeks in normal fetuses and fetuses with open spina bifida. Fetal Diagn Ther 2015;37:289293.

36. Liu M, Liu Y, Li ZH, Yu D. Screening for Fetal Spina Bifida Aperta by the Ultrasound and Intracranial Translucency Examinations at 11-13(+6) Weeks of Gestation. Cell Biochem Biophys 2015;72:439-441.

37. Robinson AJ, Ederies MA. Diagnostic imaging of posterior fossa anomalies in the fetus. Semin Fetal Neonatal Med 2016;21:312-320.

38. Loomba R, Shah PH, Anderson RH. Fetal Magnetic Resonance Imaging of Malformations Associated with Heterotaxy. Cureus 2015;7:e269.

39. Gholipour A, Estroff JA, Barnewolt CE, et al. Fetal MRI: A Technical Update with Educational Aspirations. Concepts Magn Reson Part A Bridg Educ Res 2014;43:237-266.

40. Sammet S. Magnetic resonance safety. Abdom Radiol (NY) 2016;41:444-451.

41. Yu S, Zhang R, Wu S, Hu J, Xie Y. An edge-directed interpolation method for fetal spine MR images. Biomed Eng Online 2013;12:102.

42. Nemec U, Nemec SF, Krakow D, et al. The skeleton and musculature on foetal MRI. Insights Imaging 2011;2:309318.

43. Glenn OA. MR imaging of the fetal brain. Pediatr Radiol 2010;40:68-81.

44. Simon EM, Goldstein RB, Coakley FV, et al. Fast MR imaging of fetal CNS anomalies in utero. AJNR Am J Neuroradiol 2000;21:1688-1698.

45. D‘Ercole C, Girard N, Boubli L, et al. Prenatal diagnosis of fetal cerebral abnormalities by ultrasonography and magnetic resonance imaging. Eur J Obstet Gynecol Reprod Biol 1993;50:177-184.

46. Kumar J, Afsal M, Garg A. Imaging spectrum of spinal dysraphism on magnetic resonance: A pictorial review. World J Radiol 2017;9:178-190.

47. Rathee S, Joshi P, Kelkar A, Seth N. Fetal MRI: A pictorial essay. Indian J Radiol Imaging 2016;26:52-62.

48. Sefidbakht S, Dehghani S, Safari M, Vafaei H, Kasraeian M. Fetal Central Nervous System Anomalies Detected by Magnetic Resonance Imaging: A Two-Year Experience. Iran J Pediatr 2016;26:e4589.

49. Reddy UM, Filly RA, Copel JA; Pregnancy and Perinatology Branch, Eunice Kennedy Shriver National Institute of Child Health and Human Development, Department of Health and Human Services, NIH. Prenatal imaging: ultrasonography and magnetic resonance imaging. Obstet Gynecol 2008;112:145-157.

50. 50. Jarvis D, Mooney C, Cohen J, et al. A systematic review and meta-analysis to determine the contribution of $\mathrm{mr}$ imaging to the diagnosis of foetal brain abnormalities In Utero. Eur Radiol 2017;27:2367-2380. 
51. Wang GB, Shan RQ, Ma YX, et al. Fetal central nervous system anomalies: comparison of magnetic resonance imaging and ultrasonography for diagnosis. Chin Med J (Engl) 2006;119:1272-1277.

52. Griffiths PD, Porteous M, Mason G, et al. The use of in utero MRI to supplement ultrasound in the foetus at high risk of developmental brain or spine abnormality. Br J Radiol 2012;85:e1038-e1045.

53. Beeghly M, Ware J, Soul J, et al. Neurodevelopmental outcome of fetuses referred for ventriculomegaly. Ultrasound Obstet Gynecol2010;35:405-416.

54. Nagaraj UD, Bierbrauer KS, Zhang B, Peiro JL, KlineFath BM. Hindbrain Herniation in Chiari II Malformation on Fetal and Postnatal MRI. AJNR Am J Neuroradiol 2017;38:1031-1036.
55. Sutton LN. Fetal surgery for neural tube defects. Best Pract Res Clin Obstet Gynaecol 2008;22:175-188.

56. Adzick NS, Thom EA, Spong CY, et al. A Randomized Trial of Prenatal versus Postnatal Repair of Myelomeningocele. New Engl J Med 2011;364:993-1004.

57. Danzer E, Flake AW. In utero Repair of Myelomeningocele: Rationale, Initial Clinical Experience and a Randomized Controlled Prospective Clinical Trial. Neuroembryology Aging 2008;4:165-174.

58. Johnson MP, Bennett KA, Rand L, et al; Management of Myelomeningocele Study Investigators. The Management of Myelomeningocele Study: obstetrical outcomes and risk factors for obstetrical complications following prenatal surgery. Am J Obstet Gynecol 2016;215:778.e1-778.e9. 